\title{
Repair of an Endoscopic Retrograde Cholangiopancreatography- Related Large Duodenal Perforation Using Double Endoscopic Band Ligation and Endoclipping
}

\author{
Keunmo Kim, Eun Bee Kim, Yong Hyeok Choi, Youngmin Oh, Joung-Ho Han and Seon Mee Park \\ Department of Internal Medicine, Chungbuk National University College of Medicine, Cheongju, Korea
}

Endoscopic closure techniques have been introduced for the repair of duodenal wall perforations that occur during endoscopic retrograde cholangiopancreatography (ERCP). We report a case of successful repair of a large duodenal wall perforation by using double endoscopic band ligation (EBL) and an endoclip. Lateral duodenal wall perforation occurred during ERCP in a 93-year-old woman with acute calculous cholangitis. We switched to a forward endoscope that had a transparent band apparatus. A $2.0-\mathrm{cm}$ ovalshaped perforation was found at the lateral duodenal wall. We repaired the perforation by sequentially performing double EBL and endoclipping. The first EBL was performed at the proximal edge of the perforation orifice, and two-thirds of the perforation were repaired. The second EBL, which also included the contents covered under the first EBL, repaired the defect almost completely. Finally, to account for the possible presence of a residual perforation, an endoclip was applied at the distal end of the perforation. The detection and closure of the perforation were completed within 10 minutes. We suggest that double EBL is an effective method for closure.

Clin Endosc 2017;50:202-205

Key Words: Cholangiopancreatography, endoscopic retrograde; Duodenal perforation; Endoscopic band ligation

\section{INTRODUCTION}

Endoscopic band ligation (EBL) has been widely used for the treatment of gastrointestinal hemorrhage, such as that caused by varices, ulcers, and invasive endoscopic procedures. ${ }^{1}$ EBL is also used as a reparative technique for procedure-related gastrointestinal perforations. ${ }^{2}$ It is advantageous for treating gastrointestinal perforations because it can be performed immediately after diagnosis and the required devices are commonly available in endoscopy units.

Perforation is a rare complication of endoscopic retrograde cholangiopancreatography (ERCP), occurring in approxi-

Received: August 1, 2016 Accepted: August 30, 2016

Correspondence: Seon Mee Park

Department of Internal Medicine, Chungbuk National University College of Medicine, 1 Chungdae-ro, Seowon-gu, Cheongju 28644, Korea

Tel: +82-43-269-6019, Fax: +82-43-273-3252, E-mail: smpark@chungbuk.ac.kr

(c) This is an Open Access article distributed under the terms of the Creative Commons Attribution Non-Commercial License (http://creativecommons.org/ licenses/by-nc/3.0) which permits unrestricted non-commercial use, distribution, and reproduction in any medium, provided the original work is properly cited. mately $1 \%$ of cases; however, the associated mortality rate is as high as $7.6 \%$. Immediate surgery is recommended for endoscopy-related duodenal wall perforations. Recently, several endoscopic closure techniques, such as the use of endoclips, endoloops, fibrin glue, and band ligation, have been introduced for perforation repair. However, endoscopic methods have limitations if the perforation size is larger than $1.0 \mathrm{~cm}$. To overcome this limitation, techniques that involve the use of multiple endoclips and endoloops were introduced.

We report a case of successful repair of a $2.0-\mathrm{cm}$ duodenal wall perforation, which was caused by an endoscopic tip during ERCP, by performing double EBL and using an endoclip.

\section{CASE REPORT}

A 93-year-old woman presented to the emergency department with upper abdominal pain that began 5 days prior. She had been taking oral antihypertensive agents and had no 
other underlying diseases. Initial blood pressure, heart rate, respiratory rate, and body temperature were 140/90 mm Hg, 115 beats per minute, 20 cycles per minute, and $38.5^{\circ} \mathrm{C}$, respectively. During physical examination, tenderness was noted in the right upper quadrant of the abdomen. Laboratory data were as follows: white blood cell count, 29,710 cells/ $\mu \mathrm{L}$; hemoglobin level, $9.9 \mathrm{~g} / \mathrm{dL}$; platelet count, 163,000/mL; aspartate aminotransferase, $341 \mathrm{IU} / \mathrm{L}$; alanine aminotransferase, $186 \mathrm{IU} / \mathrm{L}$; $\gamma$-glutamyltransferase, $586 \mathrm{IU} / \mathrm{L}$; alkaline phosphatase, $212 \mathrm{IU} /$ $\mathrm{L}$; total bilirubin, $1.70 \mathrm{mg} / \mathrm{dL}$; and high-sensitivity C-reactive protein, $5.67 \mathrm{mg} / \mathrm{dL}$. Abdominal computed tomography scan showed common bile duct dilatation with multiple stones in the bile duct and gallbladder. Acute cholangitis and acute cholecystitis due to gallstones were diagnosed, and ERCP was performed. While inserting the lateral endoscope from the duodenal bulb to the second portion of the duodenum, the existence of a perforation at the descending limb of the duodenum was suspected. We immediately switched to a forward endoscope that had a transparent band apparatus and attempted to confirm the presence of the perforation at
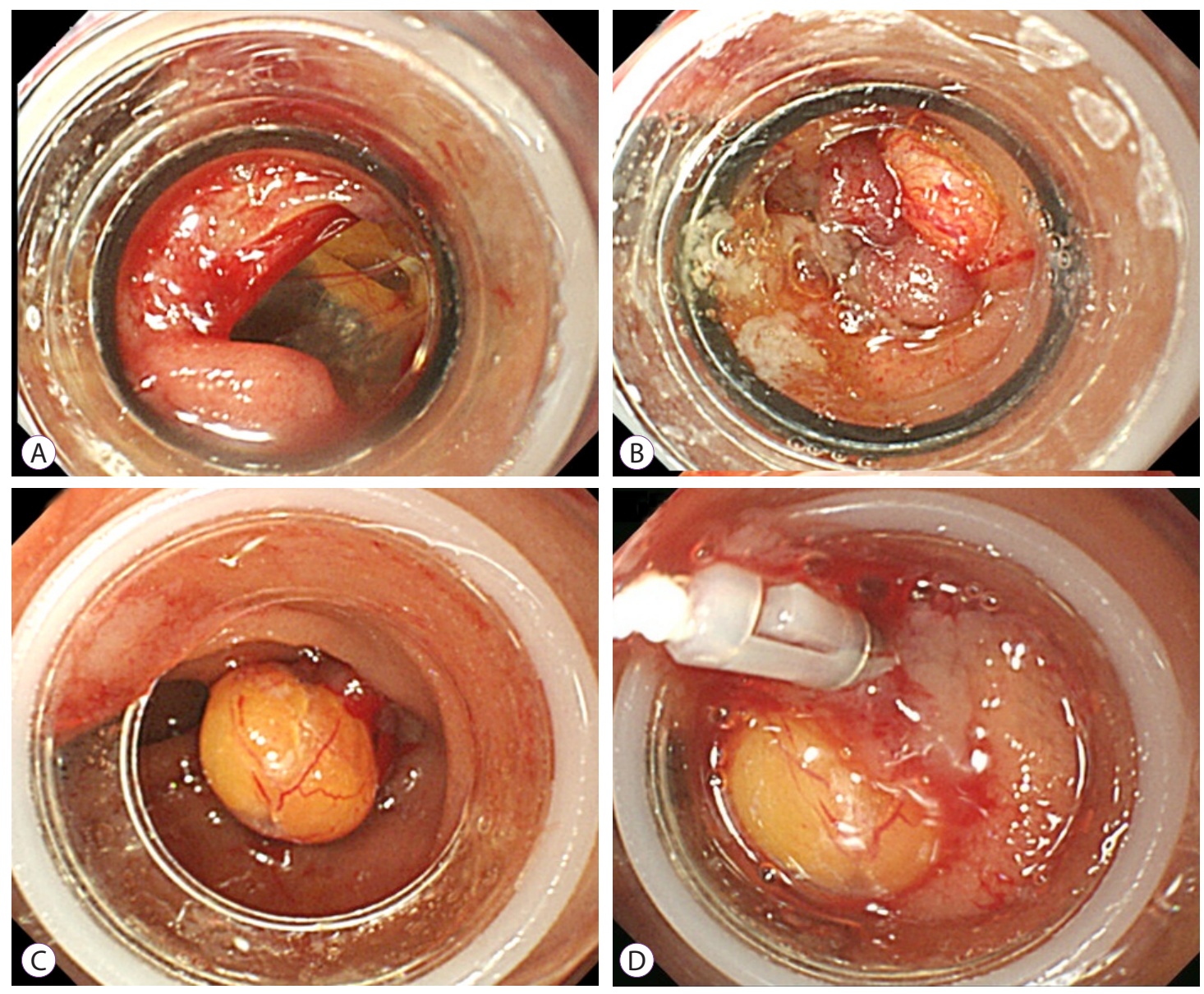

(E)

A

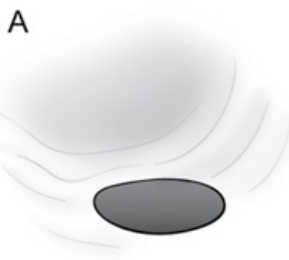

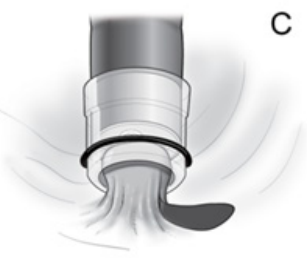

C

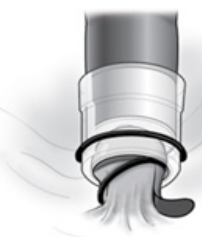

D

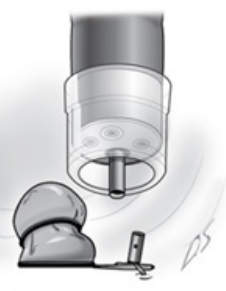

Fig. 1. Gastroscopic findings of duodenal wall perforation during endoscopic retrograde cholangiopancreatography and closure with double band ligation and endoclipping. (A) Duodenal wall perforation caused by insertion of the lateral scope into the second portion of the duodenum. The peritoneal contents were visible through the $2.0-\mathrm{cm}$ perforation. (B) Partial closure of the duodenal perforation via the first band ligation. (C) Closure of the duodenal perforation including the duodenal wall and peritoneal fat with double band ligation. (D) Complete closure of the duodenal perforation with endoclipping after double band ligation. (E) Diagrammatic representation of the band ligation and endoclipping procedures for the repair of large duodenal perforations. 
the suspected site. A $2.0-\mathrm{cm}$ oval-shaped perforation at the lateral duodenal wall was found, and peritoneal structures such as the mesenteries were observed in some areas of the perforation. A diagnosis of ERCP-related perforation of the lateral duodenal wall was made, and repair of the perforation orifice with EBL was planned. However, single band ligation is considered to be ineffective for the repair of a $2.0-\mathrm{cm}$ perforation; hence, double band ligation was attempted. The first EBL was performed at the proximal edge of the perforation orifice, and two-thirds of the perforated site were repaired along with

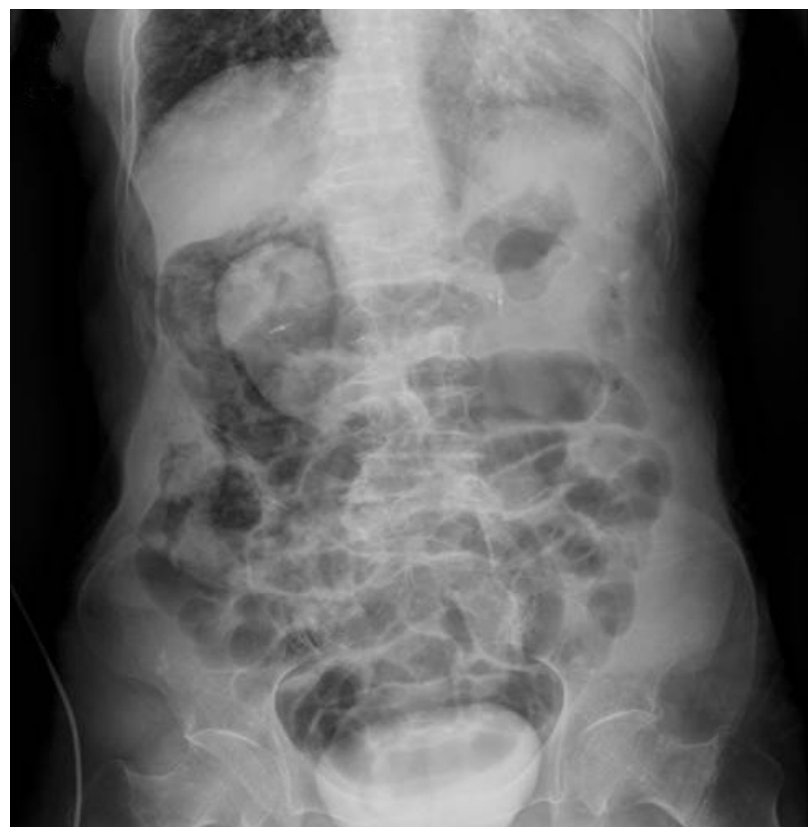

Fig. 2. Simple abdomen after the endoscopic closure procedure. No retroperitoneal air leakage was observed near the right kidney.

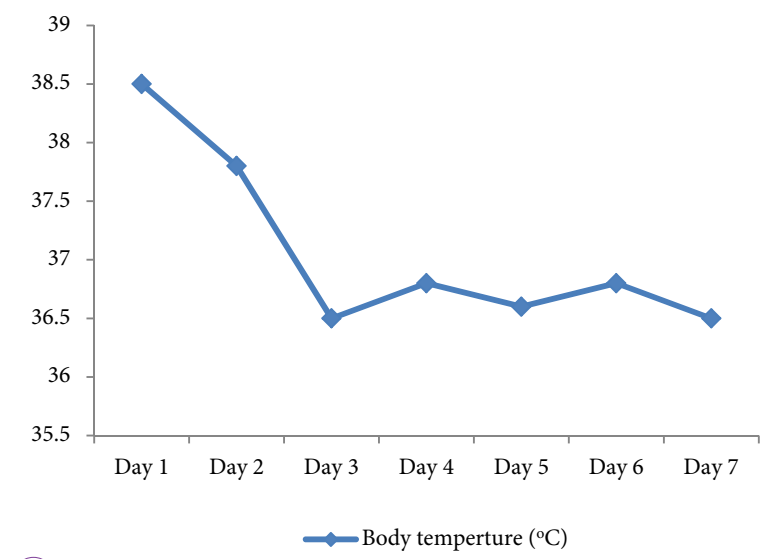

the adjacent normal duodenal structures. A second EBL was performed that included the contents covered by the first ligation. Considering the possibility of the existence of a residual perforation, an endoclip was applied at the distal end of the perforation. The diagnosis and repair of the perforation were performed within 10 minutes (Fig. 1).

Although free air was not present, an air shadow was observed near the right kidney and retroperitoneal space on plain abdomen radiography performed after the procedure (Fig. 2). The patient complained of abdominal pain accompanied by persistent right upper quadrant tenderness, and treatment comprising the administration of analgesics, antibiotics, and intravenous fluids and bowel rest was initiated. Abdominal pain improved after 24 hours. During the 1-week hospital stay, abdominal pain and fever subsided, and other laboratory tests results were within the normal limits (Fig. 3).

\section{DISCUSSION}

Various endoscopic repair methods for iatrogenic perforations have been introduced because of the increase in the number of endoscopic procedures performed. EBL, which was formerly indicated only for the management of gastrointestinal bleeding, is now widely used for perforation repair. In some cases, endoscopic clipping is impossible or insufficient owing to the size and location of the perforation, and in such cases EBL alone or in combination with endoclipping is performed. $^{2}$

In general, perforations are divided into three subtypes depending on the size: small, $<1 \mathrm{~cm}$; large, between 1 and 3 $\mathrm{cm}$; and giant, $>3 \mathrm{~cm}{ }^{3}$ The biggest advantages of EBL are that

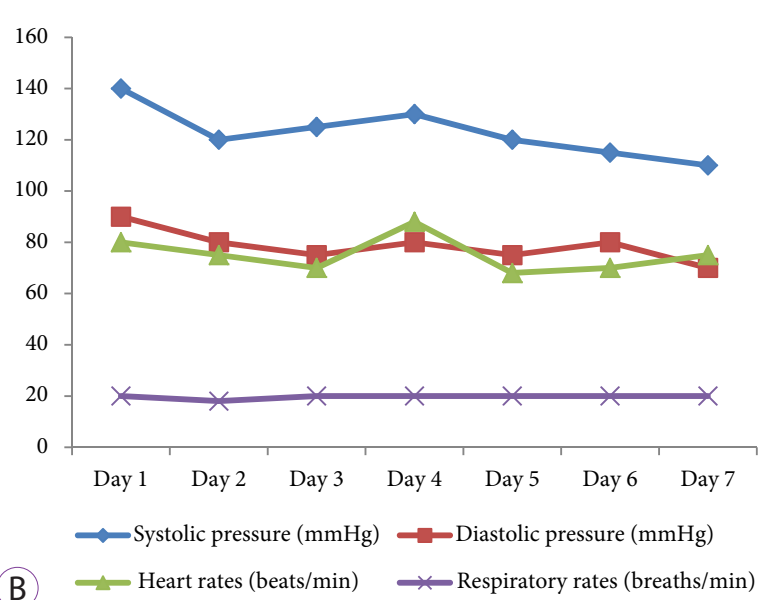

Fig. 3. The flow chart of the patient's vital signs. The vital signs remained within the normal range during the hospital stay after the patient underwent duodenal closure with band ligation and endoclipping. (A) At the day 1 and day 2, fever were noticed. (B) Blood pressures and heart rates were within normal ranges during whole hospital days. 
it can be easily performed for perforations that are 1 to $2 \mathrm{~cm}$ in size regardless of the perforation site or angle and it can be performed immediately after the perforation is diagnosed. Multiple cases of successful endoscopic repair of esophageal perforations smaller than 1.0 or 1 to $2 \mathrm{~cm}$ in size in the stomach, duodenum, and colon have been reported recently. The success of the band ligation depends on the wall structure and thickness. ${ }^{4}$ The success rate for EBL is higher when it is performed in the colon, second to fourth duodenal portions, and small bowel than when it is performed in the stomach and duodenal bulb due to its thin bowel wall structure and thickness. $^{2}$

Perforations associated with ERCP are classified into four subtypes depending on the clinical severity, pathogenesis, anatomic position, and the need for surgery. Type I (lateral and medial wall) perforations caused by the endoscope tip require immediate surgery due to the clinical severity. However, with rapid developments in endoscopic treatment methods and devices in recent years, products and techniques such as fibrin glue, ${ }^{5}$ endoloops, ${ }^{6}$ endoclips,${ }^{7,8}$ over-the-scope clipping devices, ${ }^{9}$ purse-string sutures, ${ }^{10}$ and open-pore film drainage ${ }^{11}$ have been introduced for treating type I perforations. ${ }^{12}$ The frequency of surgical or nonsurgical repair depends on the perforation type. For type I perforations, $81 \%$ are repaired surgically, whereas $79 \%$ of type II (perivaterian) and $100 \%$ of type III (guide-wire associated) or type IV (retroperitoneal air alone) perforations are repaired non-surgically.

In this case, a better clinical course was achieved by immediate clinical suspicion of type I perforation, concurrent diagnosis and treatment with the use of a forward endoscope, and minimization of air and fluid leakage into the abdominal cavity. Complete ligation was achieved by double band ligation and endoclipping at the distal site although the perforation size was larger than the typical perforation size indication for EBL. Because a better prognosis can be achieved with prompt repair, it is highly recommended to make a diagnosis by immediately switching to a forward endoscope with a band and transparent cap whenever perforation is suspected. When the endoscope band is applied to the forward endoscope, the function of the transparent cap remains unchanged. Thus, accurate visualization of the perforation site is advantageous for rapid repair. In addition, the endoscope band has the advantage that is readily available in endoscopy units and hence can be widely used for hemostasis.

In this case, we performed EBL for a 2-cm perforation. Complete repair of a perforation larger than $2 \mathrm{~cm}$ can be achieved if EBL is started from the lateral edge and the length of perforation is shortened by applying additional EBLs or hemoclipping sequentially to create a "zipper effect."

In conclusion, when type I duodenal perforation is suspected during ERCP, immediately switching to a forward endoscope with an endoscope band can aid in prompt diagnosis and repair of the perforation. Moreover, the immediate switch could minimize fluid leakage into the abdominal cavity. EBL could be used for large perforations by starting the repair from the lateral edge of the perforation site and applying additional band ligation or endoclipping if complete repair cannot be achieved with single band ligation.

\section{Conflicts of Interest}

The authors have no financial conflicts of interest.

\section{REFERENCES}

1. Van Stiegmann G, Goff JS. Endoscopic esophageal varix ligation: preliminary clinical experience. Gastrointest Endosc 1988;34:113-117.

2. Han JH, Lee TH, Jung Y, et al. Rescue endoscopic band ligation of iatrogenic gastric perforations following failed endoclip closure. World J Gastroenterol 2013;19:955-959.

3. Gupta S, Kaushik R, Sharma R, Attri A. The management of large perforations of duodenal ulcers. BMC Surg 2005;5:15.

4. Fan CS, Soon MS. Repair of a polypectomy-induced duodenal perforation with a combination of hemoclip and band ligation. Gastrointest Endosc 2007;66:203-205.

5. Stapfer M, Selby RR, Stain SC, et al. Management of duodenal perforation after endoscopic retrograde cholangiopancreatography and sphincterotomy. Ann Surg 2000;232:191-198.

6. Alfieri S, Rosa F, Cina C, et al. Management of duodeno-pancreato-biliary perforations after ERCP: outcomes from an Italian tertiary referral center. Surg Endosc 2013;27:2005-2012.

7. Mutignani M, Iacopini F, Dokas S, et al. Successful endoscopic closure of a lateral duodenal perforation at ERCP with fibrin glue. Gastrointest Endosc 2006;63:725-727.

8. Nakagawa Y, Nagai T, Soma W, et al. Endoscopic closure of a large ERCP-related lateral duodenal perforation by using endoloops and endoclips. Gastrointest Endosc 2010;72:216-217.

9. Katsinelos P, Paroutoglou G, Papaziogas B, Beltsis A, Dimiropoulos S, Atmatzidis K. Treatment of a duodenal perforation secondary to an endoscopic sphincterotomy with clips. World J Gastroenterol 2005;11:62326234.

10. Lee TH, Bang BW, Jeong JI, et al. Primary endoscopic approximation suture under cap-assisted endoscopy of an ERCP-induced duodenal perforation. World J Gastroenterol 2010;16:2305-2310.

11. Buffoli F, Grassia R, Iiritano E, Bianchi G, Dizioli P, Staiano T. Endoscopic "retroperitoneal fatpexy" of a large ERCP-related jejunal perforation by using a new over-the-scope clip device in Billroth II anatomy (with video). Gastrointest Endosc 2012;75:1115-1117.

12. Law R, Deters JL, Miller CA, Marler RJ, Baron TH. Endoscopic band ligation for closure of GI perforations in a porcine animal model (with video). Gastrointest Endosc 2014;80:717-722. 